\title{
VIRUS INCREMENT CURVES OBTAINED FROM COUNTS OF PARTICLES IN CLARIFIED PLANT JUICE ${ }^{1}$
}

\author{
Russell L. Steere ${ }^{2}$
}

DURING THE COURSE of investigations into the nature of virus multiplication a need has arisen for quantitative assays of the number of virus particles in samples of gently clarified plant juice and for additional information concerning the rate of multiplication of virus particles in the inoculated leaves of infected plants. If a strict quantitative interpretation of any non-uniformity among virus particles, as observed by electron microscopy, is to be made, certain conditions must be imposed: (1) A method must be developed for accurately assaying the number of virus particles in any sample studied. This is necessary in order to equalize, among the samples, the chances of observing deformed individuals or accidentally formed groups of two or more virus particles. (2) Curves must be obtained which will show increments in the number of virus particles in inoculated leaves as a function of the age of infection. This is necessary in order that one may be sure of comparing a rapidly-growing infection with a static one, and in order that any observed signs of a multiplication process may be quantitatively correlated with the rate of increase in the number of virus particles. Since the anticipated investigations are to involve the comparison of virus particles by electron microscopy rather than the infectivity of, or the total weight, or nitrogen content of the virus present in the various samples, the most suitable method for obtaining increment curves would be one in which the number or combined lengths of virus particles is obtained by direct measurements or counts. (3) Methods must be found for altering at will the rate of increase of virus particles in selected samples. This is desirable in order that one may compare rapidly-growing infections with static ones at the same age of infection, and hence eliminate the time factor that is implicit in the comparison mentioned under (2).

A review of methods available for assaving virus concentration in preparations from infected plants has been published recently by Takahashi (1951). Of these procedures, that employing the precipitin reaction (Beale, 1934) is the most nearly suited to a study of the concentration of virus particles in gently clarified plant juice. This method is capable of showing the presence of at least some noninfective virus particles as well as the infective ones. It has not been shown, however, that all particles of a suitable size and shape to be judged virus par-

\footnotetext{
1 Received for publication November 27, 1951.

The author gratefully acknowledges the advice and active cooperation of Professor Robley C. Williams during the progress of this research.

2 Present address: Virus Laboratory, University of California, Berkeley. This research was supported in part by a grant-in-aid from the American Cancer Society, upon recommendation of the Committee on Growth of the National Research Council.
}

ticles by electron microscopy are antigenically active. Also, the precipitin reaction is not capable of measuring particle concentration directly but requires the comparison of unknown preparations with samples of known virus content.

The first data from which plant virus increment curves could be reliably drawn were obtained by Holmes (1930). He presented tables, but could have used curves to advantage, to show the relative infectivity of tobacco leaf samples obtained at different periods of time following infection with tobacco mosaic virus. His data were obtained in the form of local lesion counts using the method he had described earlier (Holmes, 1929). His results show the relative infectivity of the various samples but are incapable of revealing the number or the combined lengths of the virus particles. It is of interest to note that he found a marked increase in infectivity of successive samples obtained during the first 4. days of infection. This was followed by a gradual increase in infectivity of samples obtained during the next 10-14 days. Curves showing the relative infectivity of samples of plant tissue following infection with tobacco mosaic virus have been presented by Grainger (1933) and by Sadasivan (1940). These curves were based on insufficient data and it is not surprising that they do not agree closely with the results obtained by Holmes and those which will be presented here.

The relative infectivity of numerous samples of juice extracted from plants infected with alfalfa mosaic virus have been presented in the form of curves by Ross (1941). A similar treatment of data obtained with tomato spotted-wilt virus was published by Samuel and Bald (1933).

Procedures recently developed in this laboratory (Backus and Williams, 1950) have made it possible to obtain quantitative assays of purified virus suspensions with the electron microscope. The possibility of developing qauntitative procedures for the determination of virus concentrations in gently clarified plant juices was suggested. Methods of clarifying infected plant juice have been simplified and a standard procedure has been developed for determining rapidly the concentration of the virus particles in small samples of plant tissue. Samples removed at intervals from the inoculated leaves of infected plants have been examined by use of this procedure and curves showing increments in the number of virus particles with age of infection have been drawn from the values obtained. Preliminary results of this research have been discussed elsewhere (Steere, 1950a,b). The standard procedure, and both normal and experimentally altered particle increment curves are presented in this paper.

Materials aNd METHODS. - Young, rapidly growing tobacco plants (Nicotiana tabacum L. var. 
"White Burley") with two or three leaves at least 3 in. long were selected with a view to uniformity. Samples from each set of plants for all experiments were prepared prior to inoculation and examined with the electron microscope for presence of tobacco mosaic virus particles.

Inoculations with tobacco mosaic virus (TMV) were made by rubbing the upper surface of each leaf of every plant with a pad of cheesecloth saturated with inoculum. The inoculum used for all experiments consisted of crude juice freshly pressed from young plants which had been infected for 1-2 weeks. It contained, therefore, approximately $10^{14}$ virus particles per ml. as will be shown later. The leaves were thoroughly washed immediately after a plant was inoculated. Then one of two procedures was followed: either cheesecloth pads were used to remove all water drops from the leaves before an initial sample was obtained, or else the plants were set aside to dry and recover from the shock of inoculation before sampling was started. In either case the inoculated plants were grown solely under artificial (fluorescent) lights at a temperature of $24^{\circ} \mathrm{C}$. following inoculation.

Samples were obtained by use of a paper punch with which dises $3 / 16$ in. in diameter were removed from definite areas of the inoculated leaves. Each area consisted of a V-shaped band across the leaf so selected as to include corresponding portions of both halves and to be bounded by adjacent secon. dary veins. From 1-6 such areas were selected per leaf (omitting the very young leaves) for each plant in an experiment. A total of 75 areas was determined for each set of plants, and a sample consisted of 75 discs, one from each area. This rather laborious sampling procedure was adopted in order to eliminate, so far as practical, errors due to variations in virus content of different plants, of different leaves on a single plant, and of different parts of a single leaf.

Clarification. - Standard procedure. - The 75 discs (totalling approximately $0.2 \mathrm{~g}$. net wt.) were ground to a fine paste in a glass micro-homogenizer immediately after they were obtained. Two $\mathrm{ml}$. of twice-distilled water were added to the paste and the mixture homogenized. The tube containing the homogenate was immersed in a $50^{\circ} \mathrm{C}$. waterbath for 5 min., and subsequently allowed to cool to room temperature. It was then placed in an angle centrifuge operated to give a field of $1200 \mathrm{~g}$. for 5 min. The supernatant liquid from this clarification was removed to a clean tube and centrifuged for another $5 \mathrm{~min}$. with the same centrifugal force. A measured portion of the supernatant liquid from the second centrifugation was transferred to a clean tube and mixed with an equal volume of water and two volumes of a standard suspension of indicator particles, PSL (Backus and Williams, 1949, 1950). This mixture was designated the basic suspension. Further twofold dilutions with once diluted stand- ard suspensions of indicator particles were made whenever necessary, in order to make certain that one mixture would contain virus and latex particles in nearly equal numbers. By such manipulation the concentration of PSL was the same in all suspensions and was thoroughly mixed with various known dilutions of clarified plant juice containing virus particles in unkown numbers.

About $0.5 \mathrm{ml}$. of each prepared suspension was sprayed onto specimen screens following the procedure of Backus and Williams (1950). Each droplet which hit the collodion film dried rapidly to form a drop residue. Specimens thus prepared were shadowed with uranium and electron micrographs were taken to 15-20 drop residues of the suspension of each sample which contained virus particles and PSL particles in approximately equal numbers. Counts of both types of particles were obtained for each drop residue photographed. Lengths of the tobacco mosaic virus particles were estimated and the monomere length of $300 \mathrm{~m} \mu$ found by Williams and Steere (1951) was adopted as a standard. The combined length in $\mathrm{m} \mu$ of all particles in a drop residue was divided by 300 to obtain the number of unit length particles recorded. It is well to mention that there was seldom any significant difference between this figure and the actual number of particles present in a drop residue. To be recorded as virus, a particle had to be the standard width for TMV, approximately $15 \mathrm{~m} \mu$, and long enough to be defined as at least a short rod. No spherical particles were included in the tabulations for this virus. For statistical purposes, approximately 400 virus particles and 400 PSL particles were counted per sample. Excentions included those samples obtained during the first $15-20 \mathrm{hr}$. after inoculation and a couple of samples which were accidentally destroved before sufficient micrographs had been obtained. During the early period of infection, virus concentration was found to be so low even in a basic suspension that it was impractical to take sufficient micrographs to count 400 virus particles. The necessary calculations were made to obtain ratios of the number of virus particles per latex particle in the basic susnension of each sample. The number of latex particles per ml. was determined by comparing the optical density of the standard suspensions used for these experiments with that of a suspension for which particle concentration was established by Williams and Backus (1949). From the counts, and from the weight and volume of a sample, the number of virus particles per gram of plant material was calculated, and a relationship was established between the $\log _{10}$ of the number of virus particles per gram green weight and the length of time after inoculation.

In order to be certain that the standard procedure was reliable for measuring the concentration of virus in gently clarified preparations, it was necessary to show that certain conditions are satisfied: 
TABle 1. Percentage disagreement between adjacent dilutions of 20 samples.

\begin{tabular}{cccc}
\hline \hline Sample & Difference in \% & Sample & Difference in \% \\
\hline 1 & 1 & 11 & 6.1 \\
2 & 1 & 12 & 7 \\
3 & 1.3 & 13 & 7.7 \\
4 & 2.3 & 14 & 8 \\
5 & 2.7 & 15 & 9 \\
6 & 3.1 & 16 & 9 \\
7 & 4 & 17 & 9.4 \\
8 & 4 & 18 & 9.8 \\
9 & 5.4 & 19 & 11.2 \\
10 & 5.5 & 20 & 12.8 \\
\hline
\end{tabular}

(1) The dispersion of virus and indicator particles in the sprayed suspension must be uniform. A uniform dispersion of indicator and purified virus particles was found by Backus and Williams (1950) in their original work with the spray drop procedure. In the present experiments all suspensions were carefully mixed and counts were made from micrographs in which virus and indicator particles were present in nearly equal numbers. In a number of cases adjacent twofold dilutions were examined to see if the particle concentrations by count agreed with the dilution.

As was expected, the ratios of virus particles to indicator particles in the various drop residues of a given dilution were found to differ. Few instances were found, however, where the value for a single drop residue was greater than 40 per cent above or below the combined value of the 12 to 20 drop residues obtained for the given sample. Among twenty samples for which adjacent dilutions were examined (see table 1), eighteen were found to agree within 10 per cent of the twofold difference expected and the other two agreed within 13 per cent.

(2) A relatively high percentage of the extractable virus must be obtained from each sample. In the first experiment (No. 1, table 2) designed to examine this problem, the pellet sedimented from the first extract was rehomogenized and a second extract obtained. A third extract was then obtained from the pellet of the second. In a second experiment (No. 2, table 2), the sediment from the

Table 2. Percentage of extractable virus obtained in first extract.

\begin{tabular}{ccccc}
\hline $\begin{array}{c}\text { Sample } \\
\text { No. }\end{array}$ & $\begin{array}{c}\text { 1st } \\
\text { extract }\end{array}$ & $\begin{array}{c}\text { 2nd } \\
\text { extract }\end{array}$ & $\begin{array}{c}\text { 3rd } \\
\text { extract }\end{array}$ & $\begin{array}{c}\text { \% in } \\
\text { Ist extract }\end{array}$ \\
\hline 1 & 69.8 & 15.5 & 2.0 & 80 \\
2 & 64.1 & 7.8 & 8.2 & 80 \\
3 & 60.7 & 15.6 & 1.3 & 78 \\
\hline
\end{tabular}

a Figures in columns 2, 3 and 4 indicate the number of virus particles per indicator particle in a standard suspension. first extract was washed to give a second extract. The sediment from this was then rehomogenized to obtain a third extract. Experiment number 3 of the series was treated similar to number 1 and with identical material but no heat was used during the clarification procedure.

As shown in table 2 , approximately 80 per cent of the virus which can be mechanically extracted by the procedure employed may be obtained in the first extract regardless of whether the preparation is heated or not. This high yield obviated the necessity of preparing more than the initial extraction from each sample.

(3) Possible variations in virus particle size and concentration due to the time required for preparation must be reduced to a minimum. To test the standard procedure for such variations, the entire operation was conducted as rapidly as possible for one sample and the results were compared with those obtained from similar samples which were allowed to stand for $24 \mathrm{hr}$. at room temperature in various stages of clarification. Though no significant differences either in particle concentration or morphology were observed among these various preparations, one cannot be certain that changes did not occur even during the most rapid preparations. Nevertheless, the time required for each step of the procedure was reduced to the minimum which would allow reliable clarification of the infected juices. The total time required to run a sample through the standard procedure is $30 \mathrm{~min}$. and one person can prepare three samples in an hour by proper timing. This does not include micrography and counting.

(4) The procedure must be capable of quantitative repetition. Three sets of experiments were conducted to study reproducibility of results. In one of these (series A), four samples were obtained simultaneously from one set of plants $150 \mathrm{hr}$. after inoculation. These were prepared by the standard procedure, and micrographs were obtained of numerous drop residues of each. In series B, four sets of plants, all inoculated at the same time, were sampled simultaneously $77 \mathrm{hr}$. after inoculation. Series C also involved sampling from four sets of plants which were inoculated at one time. For this series, however, simultaneous samplings were made at $95 \mathrm{hr}$., and again at $192 \mathrm{hr}$. This was done in order to determine whether or not there was the anticipated difference in degree of reproducibility of the procedure during different stages of infection. Close agreement was observed among the four simultaneous samplings of one set of infected plants (series A of table 3). Here a high value of 90.3 and a low of 81.9 for the number of virus particles per latex particle in the corresponding basic suspensions are noted. This amounts to a difference of 9.3 per cent. Therefore, it is believed that the methods of sampling and clarifying are sufficiently accurate to allow their use in a 
Table 3. Variation in virus content in like samples of infected plant tissue.

\begin{tabular}{|c|c|c|c|}
\hline Sample & $\begin{array}{c}\text { Duration } \\
\text { of } \\
\text { infectivity } \\
\text { hr. }\end{array}$ & $\begin{array}{l}\text { TMV/PSL } \\
\text { basic } \\
\text { suspensionn }\end{array}$ & $\begin{array}{c}\% \text { variation } \\
\text { between highest } \\
\text { and lowest } \\
\text { value obtained }\end{array}$ \\
\hline$A-1$ & 150 & 81.9 & \multirow{4}{*}{9.3} \\
\hline$A-2$ & 150 & 90.3 & \\
\hline A -3 & 150 & 83.0 & \\
\hline$A-4$ & 150 & 90.0 & \\
\hline B-1 & 77 & 28.65 & \multirow{4}{*}{24.4} \\
\hline B-2 & 77 & 29.31 & \\
\hline B-3 & 77 & 32.8 & \\
\hline B-4 & 77 & 24.8 & \\
\hline C-I & 95 & 26.18 & \multirow{4}{*}{20.0} \\
\hline C-2 & 95 & 30.5 & \\
\hline$C-3$ & 95 & 32.7 & \\
\hline C-4 & 95 & 31.75 & \\
\hline C-1-a & 192 & 71.38 & \multirow{4}{*}{12.7} \\
\hline C-2-a & 192 & 64.83 & \\
\hline $\mathrm{C}-3-\mathrm{a}$ & 192 & 62.3 & \\
\hline$C-4-a$ & 192 & 70.68 & \\
\hline
\end{tabular}

"The figures in column three show the number of virus particles per indicator particle of a "basic suspension." The fourth column gives the value for the percentage of variation between the highest and lowest figure obtained for each series. Samples of the A series were taken simultaneously from one set of plants. Those for the B and C series were taken from four sets of four plants each. It will be noted that the plants of series $C$ were sampled twice.

standard procedure for studying changes in virus particle concentrations in one set of plants.

Results obtained when the standard procedure was applied to the comparison of virus particle concentration in four separate sets of plants, were also of sufficiently close agreement that the method is considered suitable for measuring and comparing the virus concentration in various sets of plants growing under different experimental conditions. The total difference between highest and lowest values of the separate sets of plants amounted to 24.4 per cent in one experiment, and 20 per cent and 12.1 per cent in another (table 3 , series $B, C$ ). The fact that series $B$ has a difference between high and low values greater than that for series $C$ is not particularly disturbing, since four sets of only four plants each were used for this experiment, and the plants with which this particular test was conducted were not as uniform as those normally selected. They were the only plants available at the time and this was a preliminary test. One or two plants with unique resistance to infection might well be responsible for this large difference. The closer agreement between the 95-hr. samples of series C was obtained with more uniform plants. When these same plants were sampled again at 192 hr. the agreement was still closer. As one might expect, the procedure is more easily reproduced with older infections. There is almost certain to be a greater fluctuation in the number of virus particles which can be extracted from samples obtained during a period of rapid multiplication than from samples obtained during any period in which particle concentration remains constant. The figures shown bear this out. The larger number of virus particles present in the older infections might of itself tend to increase the accuracy of the procedure. Also, more complete and more uniform extraction of the virus particles from the host tissue may be possible with older infections.

With all the above conditions sufficiently satisfied, the standard procedure was employed for studies of the virus particle concentration in inoculated leaves at various periods of time following inoculation. Five independent experiments were conducted to obtain points from which normal particle increment curves were drawn. The plants for each of these differed somewhat in age and vigor, and the inoculum, consisting in all cases of freshly ground leaves from young infected plants, was different each time. Two of these experiments were conducted as controls for experiments in which the effect of increased temperature upon particle concentration was studied. ${ }^{3}$ Each was linked to two such experiments by use of plants of the same age and vigor and identical inoculum and illumination. In both of these trials one set of infected plants was placed, at the end of the first day following inoculation, in a compartment of the plant chamber which was maintained at a temperature of $38^{\circ} \mathrm{C}$. and a second set was placed in this heated compartment $54 \mathrm{hr}$. after inoculation. Values were determined for samples taken at intervals and then curves were drawn and compared with the corre sponding normal curves obtained from control plants grown at $24^{\circ} \mathrm{C}$.

A number of other experiments were conducted in an attempt to alter perceptibly the pattern of the particle increment curve. These included the use of high-and low-nitrogen nutrient solutions for which Spencer's formula (Spencer, 1939) was used and the use of standard nutrient solutions with indole-3-acetic acid in two different concentrations ( 300 p.p.m. and 100 p.p.m.). These solutions were used in separate experiments by placing the petioles of excised leaves or the roots of entire plants into them subsequent to inoculation. In other experiments a solution of yeast nucleic acid, and one of indole-3-acetic acid (each at concentrations of 100 p.p.m.), and a solution high in nitrogen were sprayed daily onto leaves of infected plants. Controls for all of these experiments consisted of samples from plants which were inoculated at the same time with the same inoculum. Since the pur-

3 The author is indebted to Dr. R. H. Larsen of the University of Wisconsin for the suggestion that high temperatures might be used to alter the increment curves experimentally. 


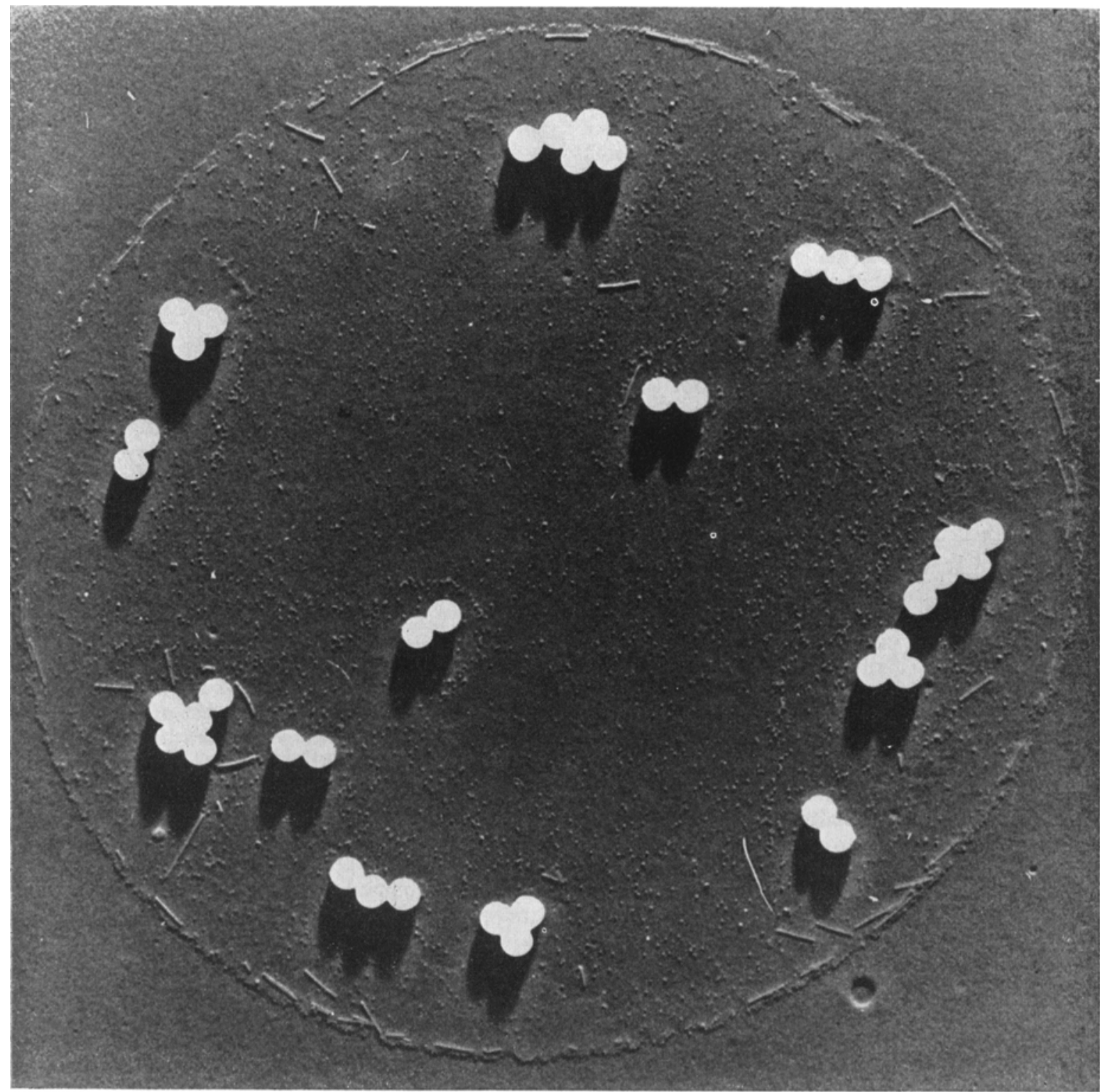

Fig. 1. Drop residue of a basic suspension of clarified juice from leaves of White Burley tobacco plants infected with tobacco mosaic virus. The large spherical particles which cast long black shadows are the indicator particles (PSL) while the narrow rods are the tobacco mosaic virus particles. $\times 20,000$.

pose of these experiments was to find some means of altering the virus increment curve, control plants were grown under the same conditions as those used for normal curves. The standard procedure was employed at several different time intervals following inoculation to determine the virus particle concentration of samples for each of the above experiments. No noticeable difference was observed between the values obtained for these experimental samples and those obtained for corresponding samples from infected controls.

A standard procedure similar to that used to obtain particle increment curves for TMV was used for tomato bushy-stunt virus (BSV). It differed in the species of host plant used, the age and size of plants at the time of experimentation, and the temperature of the waterbath in which the diluted homogenate was heated. Plants of Datura meteloides with the first two true leaves about $1 / 2$ in. long proved to be satisfactory host plants, and the waterbath temperature had to be kept at $60^{\circ} \mathrm{C}$. instead of $50^{\circ} \mathrm{C}$. in order to obtain the required clarification. Two experiments were conducted to obtain normal particle increment curves and in a 
third experiment the inoculated plants were grown in the $38^{\circ} \mathrm{C}$. chamber following inoculation.

Results.- It should be mentioned that no particles resembling those characteristic of TMV were ever observed in any of the preparations of samples obtained prior to inoculation of the various sets of plants. These preparations, therefore, served as adequate uninfected controls throughout the experiments. Control preparations for the experiments with BSV were free of particles which might be mistaken for that virus.

Fig. 1 shows an electron micrograph of a drop residue from a basic suspension of TMV in which the virus particle to indicator particle ratio was high but still satisfactory. The count for this particular drop residue was recorded as 61 tobacco mosaic virus particles and 40 latex particles. If the ratio were this high or higher for all drop residues of this preparation, a further dilution of the virus would have been made.

A normal particle increment curve for TMV reproducing in White Burley tobacco plants is shown in fig. 2 . Here the relationship between the $\log _{10}$ of the number of virus particles per gram green weight of infected plant tissue and the length of time following inoculation are shown. The diameter of the solid black circles representing each point corresponds to a 10 per cent difference in the ordinate scale. The excellent fit of the points to the curve should be noted, since only three of the twenty-two points fail to touch it. It is to be anticipated that the points obtained early in the infec. tion should be subject to large statistical fluctuations, since they are based on an inadequate num. ber of counted particles. The number of virus par.

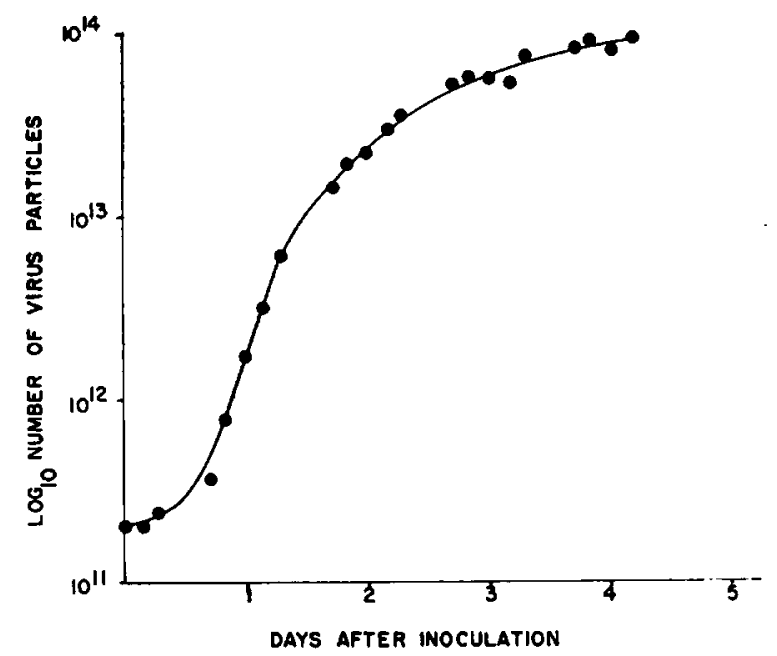

Fig. 2. Particle increment curve for tobacco mosaic virus reproducing in leaves of White Burley tobacco plants. The diameter of the circles representing each point determined corresponds to 10 per cent on the ordinate scale. This curve is repeated as the solid line curve of fig. 3 .

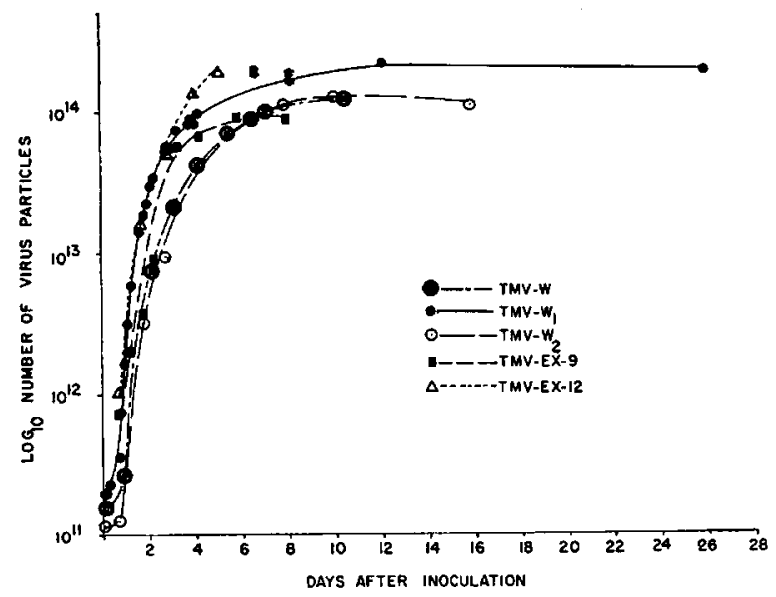

Fig. 3. Five normal particle increment curves of tobacco mosaic virus reproducing in White Burley tobacco plants. The acute points of the small triangles observed in two sets near the solid line curve on the 6th and 8 th days mark the values obtained for duplicate samples as shown in series $A$ and C-I-a to C-4-a, respectively, in table 1 . The diameter of the solid black circles corresponds to 10 per cent on the ordinate scale.

ticles in a basic suspension of the early infection was of the order of only $1 / 10$ that of the indicator particles, and as mentioned before it was impractical at this stage of infection to obtain micrographs containing enough virus particles (around 400) for good statistics. The failure of the seventeenth point to fall on the curve may be due to the fact that its value was also obtained from an insufficient number of counted virus particles (237) in a preparation containing 4 times as many indicator particles. The proper suspension for this sample was accidentally destroyed. There is little doubt that the normal increase in number of virus particles in the inoculated leaves during the first 5 days after inoculation follows a sigmoid pattern characteristic of growth curves and of autocatalytic chemical reactions.

Five normal particle-increment curves drawn through points obtained from five distinct experiments involving different batches of plants and inocula are presented in fig. 3 . The regularity with which all five curves follow the same pattern is noteworthy, especially when one remembers that the host plants were not of identical age or vigor and that the inoculum for each experiment was different. Since inoculum for all experiments was obtained from plants during the second week of infection, it became evident that all inoculum must have contained approximately $10^{14}$ virus particles per $\mathrm{ml}$. The curve of fig. 2 is repeated here (solid line) and extended to the 26th day. The points of the small arraws above the solid line curve at 6 days show the values determined for four separate samples taken from one set of plants (series A of table 3 ). 


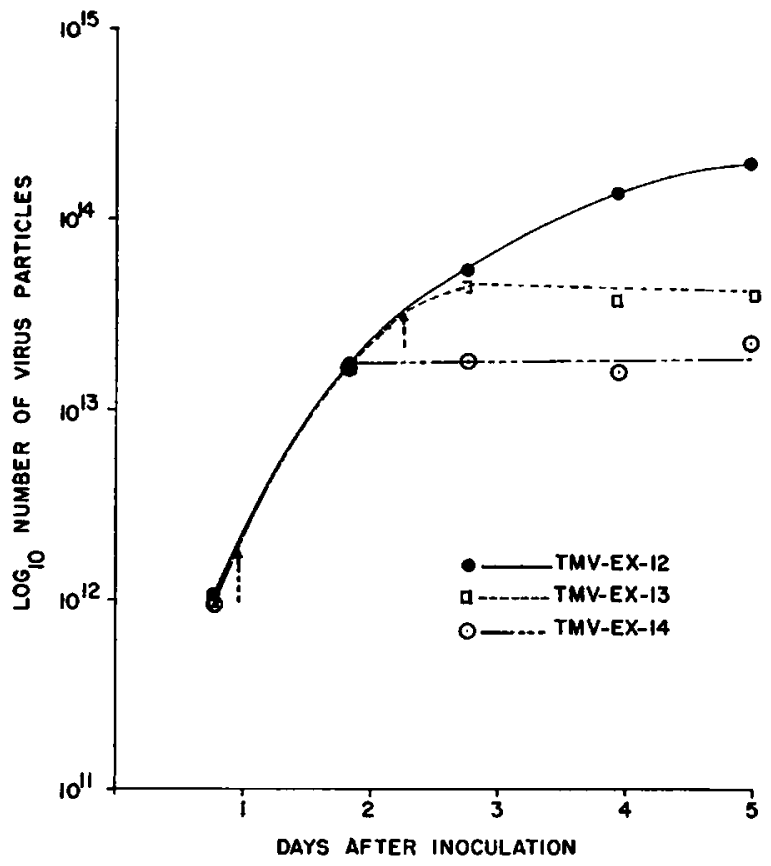

Fig. 4. Normal particle increment curve (solid line) for tobacco mosaic virus growing in leaves of White Burley tobacco plants and two curves altered by experimentally eontrolled changes in the environment in which infected plants were placed in a heated chamber kept at $38^{\circ} \mathrm{C}$. Arrows indicate the time after inoculation at which the two transfers were made. The solid black circles have a diameter corresponding to 10 per cent on the ordinate scale.

The four similar marks along the curve at 8 days show the values obtained for four samples from four separate sets of plants which were selected from a single batch of seedlings and were inoculated simultaneously (C-1-a to C-4-a of table 3 ). The positions of these last four points show that the range of variation, where the infection is static and experimental conditions are properly controlled, can be as small as 10-15 per cent.

Fig. 4 shows the results obtained from one of the sets of experiments in which two batches of inoculated plants were grown at a temperature of $38^{\circ} \mathrm{C}$. The first arrow indicates the time following inoculation at which the plants for series TMV-Ex14. were placed in the heated chamber, while the second arrow shows when the set for TMV-Ex-13 was transferred. TMV-Ex-12 was the control series maintained throughout the experiment at $24^{\circ} \mathrm{C}$. Similar results were obtained from the other set of experiments in which the same procedures were repeated.

The three curves of fig. 5 were drawn to points of counted particle concentration obtained for tomato bushy-stunt virus reproducing in Datura meteloides. The curves for experiments BSV-B and BSV-C show that the rate of increase in number of
BSV particles follows the same general pattern as that obtained for TMV. With BSV, however, the maximum concentration of virus particles is lower by a factor of 10. The BSV-C and BSV-D curves were obtained from one batch of inoculated plants. The set for the former was grown, following inoculation, at $24^{\circ} \mathrm{C}$., while that for the latter was placed immediately after inoculation in the chamber maintained at $38^{\circ} \mathrm{C}$. The BSV-C curve shows a good fit of the points in a normal series, while BSV-D failed to show any increase in virus concentration following inoculation. It must be remembered that the size and shape of this virus made clarification and identification much more difficult than was true of tobacco mosaic virus. Therefore, one would expect, under the most favorable conditions, to have a lesser degree of accuracy in the determination of points for these curves. The fact that BSV is difficult to propagate in the summertime suggested that there would not be an increase in the number of virus particles in plants grown at $38^{\circ} \mathrm{C}$., and the experimental evidence agrees.

Discussion.-The normal curves presented here for both BSV and TMV are of the standard sigmoid

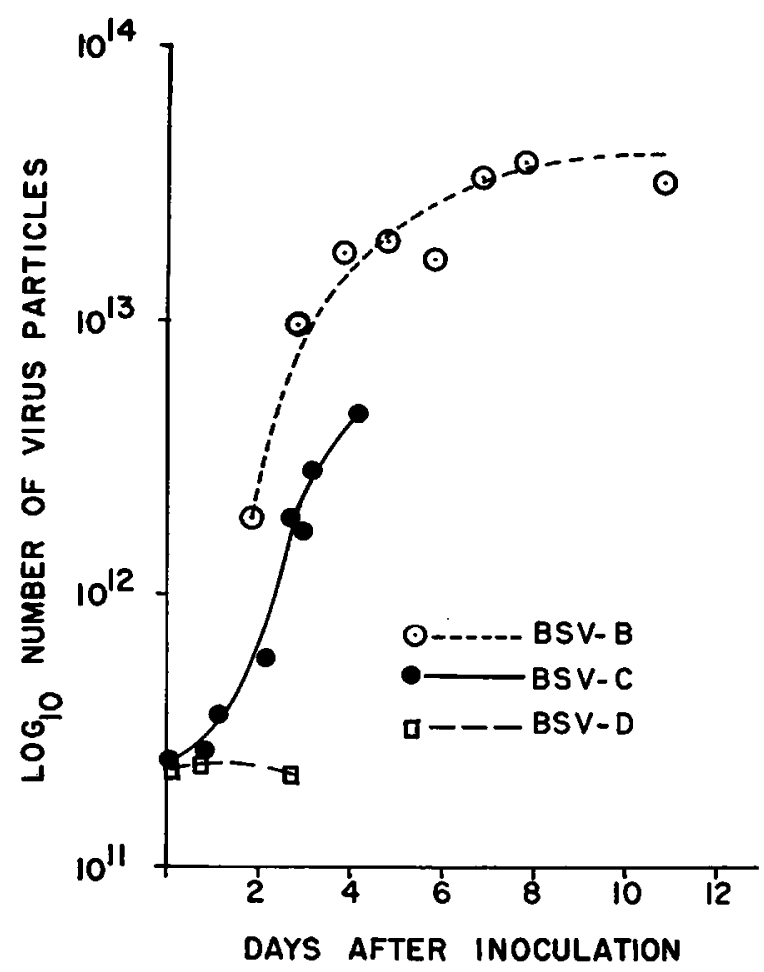

Fig. 5. Particle increment curves for tomato bushy-stunt virus reproducing in leaves of Datura meteloides plants. The plants for the BSV-C and BSB-D curves were obtained from the same inoculated seedlings. Those for the BSV.D series were placed, immediately following inoculation, in a chamber maintained at $38^{\circ} \mathrm{C}$., while those for both series A and B were maintained at $24^{\circ} \mathrm{C}$. throughout the experiments. The solid black circles again have diameters corresponding to 10 per cent on the ordinate scale. 
type frequently seen as growth curves and curves of autocatalytic reactions. There is an initial phase, which could not be accurately determined, followed by a logarithmic phase at $20-72 \mathrm{hr}$. during which time the concentration of virus particles doubles every $4 \mathrm{hr}$. This is followed by a gradual decline in the rate of increase in number of particles until a final maximum stationary phase is reached at approximately 12 days after inoculation. As mentioned before, this is the pattern of particle concentration in the inoculated leaves of infected plants and does not necessarily represent the pattern of virus increase in the entire plant. In fact, one would expect to find a somewhat different curve if samples were obtained from the growing tip of the infected plant. There would probably be a greater delay before the logarithmic period would commence and some difference might even be observed in this period due to the fact that the virus would be present in such tissue at a much earlier stage in its development. Experiments to study this have not yet been performed.

The curves of fig. 2, 3 seem to indicate that the increase in infectivity found by Holmes (1930) may be, at least in the early stages, directly correlated with the increase in virus particle concentration. In the present work no biological assay for direct comparison with the particle increment curves was made, inasmuch as the comparison would yield only a figure for the efficiency of the inoculation process under a given set of conditions.

Direct comparisons cannot be made between the curves presented here and those obtained by Ross (1941) for alfalfa mosaic virus. It is interesting to note, however, that Ross found a rapid increase followed by a rapid decrease in the relative infectivity of samples taken successively for 72 days following inoculation of tobacco plants with alfalfa mosaic virus. This is quite different from the results obtained for both tobacco mosaic and tomato bushy stunt viruses. Particle increment curves for alfalfa mosaic virus might show whether the virus is destroyed or merely inactivated after the initial multiplication.

A microanalytical method which gave results similar to those shown here was described by Commoner et al. (1950). However, they were not able to make their first determinations until the third day after inoculation and the results were obtained in milligrams of virus rather than numbers of virus particles. They reported a doubling of virus content every $24 \mathrm{hr}$. during the period of maximum virus increase. The procedure described here permits sampling immediately after inoculation, and the particle increment curves show a doubling of virus content every $4 \mathrm{hr}$. during the period of maximum reproduction.

It appears that the particle count method is superior to any other method for determining virus particle concentration in the early stages of infec- tion and at least equal to any other method for determinations made during the later stages. One must remember, however, that this method does not measure the infectivity of a virus suspension, and should be regarded as a method supplemental to that of biological assay.

The logarithmic portion of the normal increment curve (fig. 2) shows a doubling of virus content every $4 \mathrm{hr}$. If this rate of multiplication were constant from the time of inoculation, it is evident that approximately $10^{10}$ virus particles per gram green weight must have entered the inoculated tissue and begun to reproduce immediately. If every receptor point on the inoculated leaves received one actively reproducing particle it is doubtful if more than $10^{4}$ particles could be accounted for per gram green weight. Does this mean that many particles entered the receptor points and became active participants in the virus multiplication, or that far fewer particles than indicated entered into the multiplication and that the rate of multiplication was much faster during the first $20 \mathrm{hr}$. of inoculation than the curve indicates? Could the portion of the curve which appears to be a straight line actually be the beginning of a decline in the rate of increase? The points obtained during the first few hours after inoculation do not shed any light upon this problem since virus particles extracted at this stage may come from the surface of the leaf as well as from inside the inoculated tissues, and they maye be accounted for whether or not they are active in the production of additional virus particles. Further studies are necessary before we can hope to know the answers to such questions.

A value of 11.7 per cent has been determined as the percentage by dry weight of plant tissue which may be present in highly infected tobacco plants as extractable virus particles. This value is based upon the virus particle concentration $\left(2.2 \times 10^{14}\right.$ particles per gram green weight) of the highest point on the solid line curve of fig. 2 and upon the particle weight of TMV $\left(49 \times 10^{6} \mathrm{~g} . /\right.$ mole $)$ determined in this laboratory (Williams et al., 1951). In the determination of this value no correction was made for the extractable virus which was not obtained in the first extract nor for virus which cannot be extracted mechanically. Therefore. it is presumed that this is a conservative value and that an even higher percentage of the dry weight of fully diseased plant tissue may be virus. This value is greater than the figure ( 10 per cent dry weight) obtained by Bawden and Pirie (1946) through the use of snail enzymes.

An interpretation of the curves of fig. 4 is difflcult. Why was there a continued increase in virus concentration of TMV-Ex-14 for some $20 \mathrm{hr}$. after application of the heat treatment, and then an abrupt end to further increase, whereas TMV-Ex-13 showed little or no additional production of virus 
following application of the heat treatment? Is this difference due to changes in the virus or the plant? One explanation might be that there is in an uninfected plant a reserve of plant constituents necessary for the production of virus, and that as the virus multiplies this reserve is depleted to a point where equilibrium is established, with the reserves being built only as fast as they are used by the virus. It might be further that the application of heat prevents the production of reserves, but does not destroy those already present. In these events, the application of heat quite early in the infection (as with TMV-Ex-14) would allow the virus to multiply by the depletion of abundant unused reserves, whereas the application of heat after equilibrium is established (as with TMV-Ex-13) would allow for only a very brief continuation of virus multiplication. Another possible explanation is that the essentials for virus duplication are produced by the plant at the same rate at which they are utilized, and that the high temperature treatment disrupted the production of these materials. On this theory one might interpret the results as indicating that the first batch of plants placed in the $38^{\circ} \mathrm{C}$. chamber had suffered little pathological change and was able to continue normal production of essential materials for another $24 \mathrm{hr}$., whereas the second batch of plants was quite highly infected and was prevented almost immediately from producing further essential requirements for virus multiplication. One could hardly explain the results obtained here on the basis of attenuation of virus by high temperatures (Johnson, 1926, 1947; Holmes, 1934). If attenuation were responsible for the failure of virus to reproduce, the effect should be equally rapid no matter what the stage of infection at time of treatment. Further experi- ments are anticipated for a careful examination of this problem.

\section{SUMMARY}

Curves showing the increment in number of virus particles following inoculation have been obtained for tobacco mosaic virus multiplying in plants of White Burley tobacco and for tomato bushy-stunt virus multiplying in plants of Datura meteloides. Representative samples of infected plant tissue were homogenized, diluted with distilled water, clarified, diluted further with a suspension of indicator particles and deposited in the form of minute droplets on prepared specimen films. Electron micrographs were taken of numerous drop residues and the numbers of virus and indicator particles in each were counted. From these counts and from the known indicator particle concentration and dilution factors, the concentration of virus particles in each sample was determined. The normal particle increment curves for both viruses resemble standard sigmoid growth curves and curves of autocatalytic reactions. There is an initial unresolved phase followed by a logarithmic phase at 20-72 hr., during which period the virus concentration doubles every $4 \mathrm{hr}$. Then follows a maximum stationary phase with as much as 11.7 per cent, dry weight, of the leaf tissue present as virus particles. Experimentally altered curves were produced by placing infected plants in a chamber kept at $38^{\circ} \mathrm{C}$. These curves show an immediate cessation of virus multiplication at this temperature, when the treatment is applied $54 \mathrm{hr}$. after inoculation, but a retarded cessation when treatment is applied at $24 \mathrm{hr}$.

\footnotetext{
Harrison M. Randall Laboratory of Physics

and Department of Botany,

UNIVERSITY OF Michigan,

ANN Arbor, Michigan
}

\section{LITERATURE CITED}

Backus, R. C., and R. C. Williams. 1949. Small spherical particles of exceptionally uniform size. Jour. App. Physics 20: 224-225.

—_ AND - . 1950. Use of spraying methods and of volatile suspending media in the preparation of specimens for electron microscopy. Jour. App. Physics 21: 11-15.

Bawden, F. C., And N. Pirie. 1946. The virus content of plants suffering from tobacco mosaic. Jour. Exp. Path. 27: 81-90.

Brale, H. P. 1934. The serum reactions as an aid in the study of filterable viruses of plants. Contrib. Boyce Thompson Inst. 6: 407-435.

Commoner, B., F. L. Mercer, P. Merrild, and A. J. ZimMER. 1950. Microanalytical determination of the rate of tobaceo mosaic virus synthesis in tobacco leaf tissue. Arch. Biochem. 27: 271-286.

Grainger, J. 1933. The movement of tobacco mosaic virus in its host. Ann. App. Biol. 20: 236-257.

Holmes, F. O. 1929. Local lesions in tobacco mosaic. Bot. Gaz. 87: 39-55.
1930. Local and systemic increase of tobacco mosaic virus. Amer. Jour. Bot. 17: 789-805.

1934. A masked strain of tobacco mosaic virus. Phytopath. 24: 845-873.

Jornson, J. J. 1926. The attenuation of plant viruses and the inactivating infuence of oxygen. Science 64: 210 .

- 1947. Virus attenuation and the separation of strains by specific hosts. Phytopath. 37: 822-837.

Ross, A. F. 1941. The concentration of alfalfa-mosaic virus in tobacco plants at different periods of time after inoculation. Phytopath. 31: 410-420.

Sadasivan, T. S. 1940. A quantitative study of the interaction of viruses in plants. Ann. App. Biol. 27: 359-367.

Samuel, G., and J. G. Bald. 1933. On the use of the primary lesions in quantitative work with two plant viruses. Ann. App. Biol. 20: 70-99.

Spencrer, E. L. 1939. The effect of host nutrition on con. centration of tobacco mosaic virus. Plant Physiol. 14: 769-782.

Stefre, R. L. 1950a. Plant virus growth curves as de- 
termined by use of the electron microscope. ( $A$ bstract) Jour. App. Physics 21:70.

_ 1950b. Virus increment curves based upon counts of particles in plant juice prepared by new and rapid procedures for electron microscopy. Dissertation. Univ. of Michigan. Ann Arbor.

TAKAHASH, W. N. 1951. Ultraviolet absorption as a measure of tobacco mosaic virus nucleoprotein. Phytopath. 41: 142-145.

Williams, R. C., And R. C. Backus. 1949. Macromolecular weights determined by direct particle counting. I. The weight of the bushy stunt virus particle. Jour. Amer. Chem. Soc. 71: 4052-4057.

-, AND R. L. SteERE. 1951. Macromolecular weights determined by direct particle counting. II. The weight of the tobacco mosaic virus particle. Jour. Amer. Chem. Soc. 73: 2062-2066.

, ANd R. L. Steere. 1951. Electron microscopic observations on the unit length of the particles of tobacco mosaic virus. Jour. Amer. Chem. Soc. 73: 2057-2061.

\section{THE COMPARATIVE ANATOMY OF THE XYLEM AND THE PHYLOGENY OF THE JULIANIACEAE ${ }^{1}$}

\section{William L. Stern}

The natural afFinities of the Julianiaceae have been debated ever since the description of the genus Juliania (then Hypopterygium) by von Schlechtendal in 1843. Most workers who have investigated the internal anatomy of the group are inclined to place the family close to the Anacardiaceae. Thus Fritsch (1908) suggested that one of the chief points of resemblance between Julianiaceae and Anacardiaceae lies in the occurrence of large resin-containing canals in the phloem and pith of both families. Both Rhus simulata and Spondias mangifera were found "... to possess such resincanals in the leaf in exactly the same position ..." as in Julianiaceae. Copeland and Doyel (1940), in their study of the anatomy of Toxicodendron diversiloba, give several points which in their opinion indicate a close relationship between Julianiaceae and Anacardiaceae. Copeland and Doyel, referring to Boodle's work which is included in Hemsley's (1908) paper, show that Toxicodendron and julianiaceous ovules agree in orientation, vascular supply, and the presence of a hypostase. The embryos are also similar in the peculiarly oriented radicle, and in the shape of the margins of the cotyledons. I. W. Bailey (as quoted in Copeland and Doyel) is of the opinion that the secondary xylem of Julianiaceae and Anacardiaceae is so alike that the two might be grouped in a single family. In his study of the secondary xylem of Wettstein's Gruinales and Terebinthales, Heimsch (1942) agrees that the Julianiaceae are closely related to the Anacardiaceae. Standley (1923), and Standley and Steyermark (1949), in writing of Juliania adstringens, state that the simple-leaved form, reduced from compound, sometimes found here, indicates a

1 Received for publication October 9, 1951.

Grateful acknowledgment is made to Professor Oswald Tippo for his assistance with the problem; to Mr. Theodore Delevoryas for his skill in photography; to Professor G. Neville Jones for his help with the taxonomic portions of the work; to Dr. Theodor Just for making herbarium facilities available; to Mrs. Martha Leavenworth for gift of materials; to Professor Charles Heimsch for loan of slides; to Dr. G. Erdtman for his analysis of pollen; and to my wife who typed the manuscript. relationship with Anacardiaceae and Burseraceae for similar kinds of compound leaves are found in certain species of Bursera and Rhus. In these species, leaves on the same branch may vary from unifoliolate to trifoliolate, and even 5-7 leaflets.

In direct contrast to this theory, Rose, in a letter quoted in Hemsley (1908), states that he does not believe that the group has any relationship with either Burseraceae or Anacardiaceae and ". . . that it must be closely related to the Juglandaceae . . .". Macbride (1936) believes the resemblances of the Julianiaceae with Juglandaceae may be more fundamental than those with Anacardiaceae. He points to the presence of unisexual flowers which are common to both Juglandaceae and Julianiaceae. The Julianiaceae are placed in a distinct order, the Julianiales, by Johnson (1931), Engler and Diels (1936), and Rendle (1938). Each of these workers places the order in close proximity to the Juglandales. Hutchinson (1926), and Wettstein (1935), place the family Julianiaceae under the order Juglandales with the family Juglandaceae. Hallier (1905) treats the genera of Julianiaceae as a tribe (?) under the family Juglandaceae co-existent with Juglandeae. However, in 1908, he revised this conception and said that Juliania had arisen from Pistacia through the reduction of the pistillate flowers. Therefore, he placed Juliania in the family Terebinthaceae. Hemsley (1908), after considering other possible affinities of the Julianiaceae, came to the conclusion that the family was most closely related to the "Cupuliferae." He based his opinion on the common possession of a closed involucre in Juliania, Fagus, Castanea, and Castanopsis; the similarity of the male flowers, inflorescences, and pollen in Juliania adstringens and certain species of Quercus; the "collateral" flowers and nuts in Castanea and Juliania; the exendospermous seeds of Juliania and the "Cupuliferae"; and the fact that the cotyledons of Juliania and the "Cupuliferae" are epigeal in germination. On these bases he suggested that the family be placed between the Juglandaceae and the "Cupuliferae." According to Kershaw (1909), additional evidence for Hems- 